\title{
Infiltration Behavior of Thermosets for Use in a Combined Selective Laser Sintering Process of Polymers
}

\author{
KATRIN WUDY (10 ${ }^{1,2,3}$ and DIETMAR DRUMMER ${ }^{1,2}$ \\ 1.--Institute of Polymer Technology, Friedrich-Alexander-Universität Erlangen-Nürnberg, \\ 91058 Erlangen, Germany. 2.-Collaborative Research Center 814 - Additive Manufacturing, \\ Friedrich-Alexander-Universität Erlangen-Nürnberg, 91058 Erlangen, Germany. 3.-e-mail: \\ wudy@lkt.uni-erlangen.de
}

\begin{abstract}
Selective laser sintering (SLS) of polymers is an additive manufacturing process that enables the production of functional technical components. Unfortunately, the SLS process is restricted regarding the materials that can be processed, and thus the resulting component properties are limited. The investigation in this study illustrates a new additive manufacturing process, which combines reactive liquids such as thermoset resins and thermoplastics to generate multi-material SLS parts. To introduce thermoset resins into the SLS process, the time-temperature-dependent curing behavior of the thermoset and the infiltration have to be understood to assess the process behavior. The curing properties were analyzed using a rotational viscometer. Furthermore, the fundamental infiltration behavior was analyzed with microdosing infiltration experiments. Additionally, the infiltration behavior was calculated successfully by using the Washburn equation. Finally, a thermoset resin in combination with a dosing system was chosen for integration in a laser sintering system.
\end{abstract}

\section{INTRODUCTION}

Additive manufacturing technologies, such as selective laser sintering (SLS) of thermoplastic powders, generate components directly from a CAD data set without needing a form or a mold. Thus, the layer-wise process of selective laser sintering allows the generation of individualized complex serial parts. Contrary to conventional manufacturing techniques such as injection molding, which are optimized for high-volume production and low unit costs, the costs for additive manufactured parts are almost independent from the degree of complexity and quantity. ${ }^{1}$ The advantages of additive technologies are beneficial for products with a high level of customization and complexity as well as small lot sizes, known as "mass customization". ${ }^{2}$

Although efforts have been made to develop new materials for SLS ${ }^{3-7}$ the availability of polymers that can be processed in SLS is still very limited compared with conventional manufacturing methods. Besides polyamide 12 and polyamide 11 , filled systems and a few other thermoplastic materials such as polypropylene and thermoplastic elastomers are available on the market. ${ }^{8}$ The reason for the slow development of new polymer powders for SLS is the low market value. The market for SLS powders is $900 \mathrm{t} /$ year, which compared with the 260 million tons of plastic used worldwide is very small. ${ }^{8}$ Nevertheless, there is huge customer demand for new applications of additive technologies. The limited component characteristics that can be achieved with the available materials hinders the use of SLS for specific applications. The local adjustment of certain properties and thus the generation of multi-material parts could lead to significantly higher rates of usage of SLS manufactured parts, because the achieved properties could cover more specifications. Therefore, in this article a new unique additive manufacturing process will be introduced. This technology has the potential to overcome the barrier to creating new properties in SLS. The hybrid process between powder binder techniques or rather binder jetting 3D printing and SLS integrates reactive liquids in the SLS process, as shown in Fig. 1. These fluid materials will be injected into a conventional SLS powder bed 

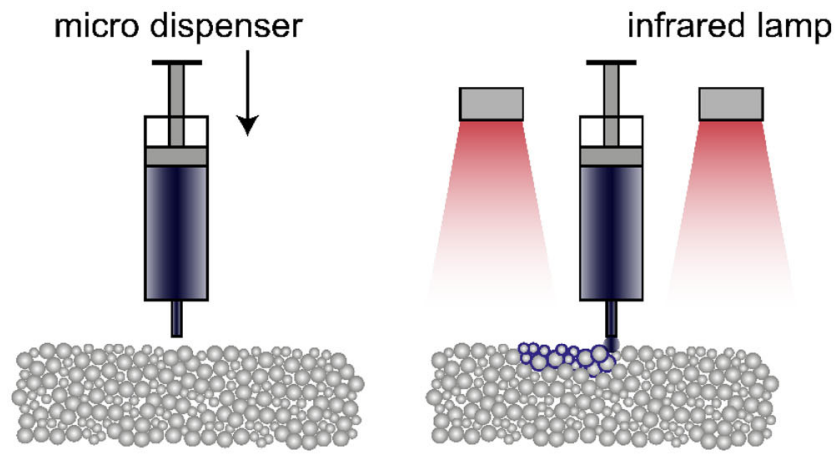
melting of SLS powder with a $\mathrm{CO}_{2}$ laser

Fig. 1. Schematic visualization of the hybrid SLS process with reactive liquids.

through a micro-valve system and the curing reaction of the liquid initiated via IR or UV radiation. Besides the reactive liquid, the thermoplastic powder can be processed in SLS as usual. Thus, multimaterial parts consisting of a reactive system such as an epoxy resin and a thermoplastic material can be generated in one process.

\section{STATE OF THE ART}

The SLS process itself can be divided into three temperature phases: the preheating, building and cooling phases. ${ }^{9}$ The building process consists of the three steps: material coating, energy input and consolidation. First, a layer of powder is applied in the building chamber. The layer thickness of the coated layer is usually between $80 \mu \mathrm{m}$ and $150 \mu \mathrm{m}$. Second the cross section of the component is exposed by a $\mathrm{CO}_{2}$ laser and the materials starts to melt selectively. Finally, the building platform is lowered by the thickness of one layer and the three process steps will be repeated. During the building process, the building chamber is preheated to a temperature near the onset melting temperature but above the crystallization temperature. ${ }^{10}$ A typical time for building one layer and thus repeating the three process steps is $40 \mathrm{~s}^{9}$ The temperatures of the surrounding powder and exposed components decrease the farther away the point of measurement is from the powder surface. ${ }^{11}$ The implementation of the reactive liquid in the hybrid process must be done after material coating and before or parallel to the energy input via $\mathrm{CO}_{2}$ laser. The boundary conditions a liquid material has to fulfill to be implemented in the SLS process are:

- high stability at building chamber temperature

- specific curing behavior under the temperature occurring in SLS

- high infiltration rate, which goes along with a low viscosity and a defined surface tension between the solid and liquid

- separation of the two components may not occur
Thus, introducing a material that cures during the SLS process presents specific challenges. To develop thermosets for the SLS process, the curing under a specific temperature profile, determined by the SLS process itself, must be monitored precisely. The thermal household during SLS will be influenced for example by the energy input (laser power, scan speed, etc.), number of exposed components, and chamber and feeder temperature. Besides the curing of the resin, the infiltration of the liquid in the powder bed is of main importance because it ensures a sufficient connection between the two layers. The speed of infiltration and wetting of a powder layer by the used liquid does not just depend on the viscosity, but also on the surface tension $\sigma$ and other characteristics. ${ }^{12}$

The absorption or rather interaction of droplets with porous media is studied both experimentally and numerically in different investigations. A short overview of relevant investigations is shown in. ${ }^{13}$ The interaction of a droplet with porous media can be divided into the stages of initial spreading, absorption or infiltration, and evaporation. The spreading kinetics is typically characterized by an equation of the following form: ${ }^{14}$

$$
r(t)=Q \cdot t^{n}
$$

with $r$ the time-dependent droplet radius and the constants $Q$ and $n$.

For the analysis of the infiltration, or rather absorption, the porosity of the bulk materials plays a major role. Porosity can be assumed as a network of capillaries, which are in the simplest case a collection of cylindrical capillaries. Due to this simplification, equations that describe the capillary flow in a bundle of parallel cylinder tubes, such as the Washburn equation, ${ }^{14}$ can be used. According the Washburn equation, the penetration length of a liquid into a cylinder can be described with the following equation: ${ }^{14}$

$$
h(t)=\sqrt{\frac{\gamma_{\mathrm{LV}} \cdot \cos \theta \cdot R_{\text {pore }} \cdot t}{2 \eta}}
$$


with $R_{\text {pore }}$ the pore radius, $\gamma_{\mathrm{LV}}$ the surface tension of the liquid, $\theta$ the contact angle between the liquid and solid, and $\eta$ the viscosity.

Bulk materials are porous systems with cylindrical pores that are not exact. They build two- and three-dimensional networks of pores. To implement this deviation of the pore form from the idealized cylinder, a form factor $\alpha$ can be added to the Washburn equation:

$$
h(t)=\sqrt{\frac{\gamma_{\mathrm{LV}} \cdot \cos \theta \cdot R_{\mathrm{pore}} \cdot \alpha \cdot t}{2 \eta}}
$$

Denesuk et al. ${ }^{15}$ expanded the Washburn equation, assuming radial symmetry of the liquid and porosity parameters and neglecting the finite size of the pore. The infiltrated volume $V_{\mathrm{p}}$ at time can be calculated with the following equation:

$$
\begin{gathered}
V_{\mathrm{p}}(t)=\frac{k}{2} \int_{0}^{t} \frac{r^{2}\left(t^{\prime}\right)}{\sqrt{t^{\prime}}} \mathrm{d} t^{\prime} \\
k=\pi \cdot a_{\mathrm{p}} \sqrt{\frac{\gamma_{\mathrm{LV}} \cdot \cos \theta \cdot R_{\mathrm{pore}}}{2 \eta}}
\end{gathered}
$$

with $R_{\text {pore }}$ the pore radius, $a_{\mathrm{p}}$ the area fraction of pores, $\gamma_{L V}$ the surface tension of the liquid, $\theta$ the contact angle between the liquid and solid, and $\eta$ the viscosity.

Holman et al. ${ }^{12}$ studied the spreading and infiltration behavior of small droplets (approximately $60 \mu \mathrm{m}$ ) of aqueous polymer solutions on high-greendensity porous beds. The spreading and infiltration occur in this investigation at the same time scale, precluding their treatment as separate phenomena. ${ }^{12}$ Tan $^{13}$ studied the $\mathrm{pL}$ impact with porous media with computational fluid dynamics (CFD) and validation via high-speed imaging and used a similar setup as described in this article. Nevertheless, the named study focuses on the inkjet process with aqueous inks and paper as substrate.

The aim of this investigation is to analyze the spreading and infiltration behavior with a specific test setup and determine whether spreading and infiltration can be separated. Furthermore, the influence of the pore size or rather bulk density as well as the surface tension of the used liquid on the infiltrations behavior is of main interest.

\section{METHODOLOGY}

\section{Material/Powder}

For the following investigations, an unmodified PrimePart ST PEBA 2301 polyether block polyamide powder (PEBA) from the supplier EOS $\mathrm{GmbH}$, Germany, is used. PEBA is a thermoplastic elastomer consisting of polyamide and polyether backbone blocks. Two different aging states of the powder, virgin and used powder, were implemented

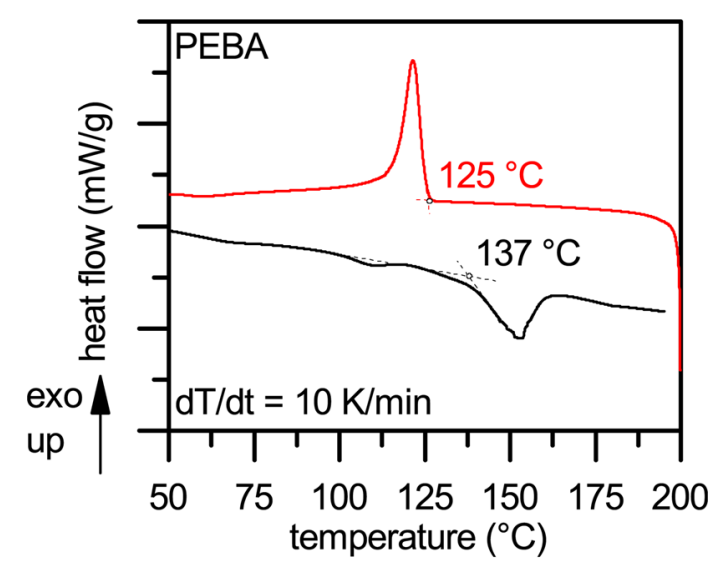

Fig. 2. DSC diagram of the used PEBA powder.

to analyze the infiltration behavior dependent on the bulk density of the material.

A DSC diagram of the used PEBA is shown in Fig. 2. Based on the DSC analysis, the chosen building chamber temperature should be between $125^{\circ} \mathrm{C}$ and $137^{\circ} \mathrm{C}$ for this material. Furthermore, material properties of the used resins such as surface tension and viscosity are of main interest at a temperature interval near the building chamber temperature. Due to reduction of the temperature during coating machismo of up to $30 \mathrm{~K}$, the relevant temperature range is between $100^{\circ} \mathrm{C}$ and $130^{\circ} \mathrm{C}$.

\section{Material/Resins}

As reactive liquid, two epoxy resins, Araldite GY 764 and Araldite GY 793, purchased from Huntsman Advanced Materials, Switzerland, were used. Araldite GY 764 is based on bisphenol A, whereas GY 793 is based on bisphenol A/F. The used curing agent, Hardener XB 3473, was also purchased from Huntsman Advanced Materials. The used mixing ratios were 100:23 parts per weight for GY 764 and 100:22 parts per weight for GY 793. The epoxy resins were selected because of their low viscosity and high reaction temperatures, which made them compatible with the sought processing through a micro-valve in the hot building chamber. GY 764 has a viscosity of $350-550 \mathrm{mPas}$, GY 793 650$750 \mathrm{mPas}$ and the Hardener XB $3473 \quad 80-$ 125 mPas. ${ }^{16}$ For the further investigations, the mixtures of Araldite and Hardener are abbreviated with the pure resin names Araldite GY 764 and Araldite GY 793.

\section{Characterization of Material Properties}

The surface tension of the used resins was analyzed with the pendant drop method and the surface tension measurement setup from DataPhysics. At least ten drops were dosed and evaluated according to their dimensions. The Laplace-Young equation was used to calculate the surface tension of the liquid. 
The viscosity of the resins was determined with a Discovery HR-2 rotational viscometer from TA Instruments. As measurement geometry, a plateplate setup was used. The frequency was set to 0.1 Hertz, and the normal force was $10 \mathrm{~Pa}$. The uncured mixture was applied between the two plates at a starting temperature of $25^{\circ} \mathrm{C}$, and the specimen was heated at a rate of $2 \mathrm{~K} / \mathrm{min}$ up to $200^{\circ} \mathrm{C}$. Finally, the complex viscosity was analyzed depending on the temperature.

Besides the influence of the temperature, the influence of the bulk density on the infiltration behavior was investigated. Therefore, the bulk density was analyzed according to DIN EN ISO 60 . The bulk density is defined as the mass of the polymer particles divided by the total volume they occupy. For the analysis, an ADP bulk density tester from Emmeran Karg Industrietechnik was used. The average of at least five measurements was calculated.

\section{Infiltration Behavior}

For the combined laser sintering process, the infiltration behavior of the reactive liquid in the powder bed is of main interest. Therefore, the infiltration behavior was analyzed with a specific test setup, which is schematically illustrated in Fig. 3. For the measurements, a basic setup from DataPhysics was used. This system is used to determine the surface tension of liquids with the pendant drop method and the surface tension of solids with the sessile drop method. The sessile drop measuring mode was adapted to determine the development of the drop height depending on time. Thus, the infiltration of the liquid in the powder bed can be evaluated. Furthermore, the angle between the powder bed surface and the liquid was analyzed.

With a microliter syringe, a resin drop was applied on the powder bed surface. The drop is illuminated from one side by a light source and observed by a CCD camera system on the other side. The infiltration of at least ten drops was measured to calculate an arithmetic average. The development of the drop height and contact angle was measured at $20^{\circ} \mathrm{C}, 40^{\circ} \mathrm{C}$ and $60^{\circ} \mathrm{C}$ under nitrogen atmosphere. Figure 2 shows that the temperature range between $100^{\circ} \mathrm{C}$ and $130^{\circ} \mathrm{C}$ is of primary interest because of the building chamber temperature. Nevertheless, the infiltration at these temperature takes $<1 \mathrm{~s}$ and is hardly analyzable. Table I represents the detailed design of experiments.

\section{RESULTS AND DISCUSSION}

First, the bulk density of the used substrate materials, a thermoplastic elastomer with a volumetric median particle size of $77 \mu \mathrm{m}$, was analyzed. As substrate material, virgin powder and powder that had passed through one processing cycle were chosen. The virgin powder shows an average bulk density of $0.39 \mathrm{~g} / \mathrm{cm}^{3}$. With increasing numbers of

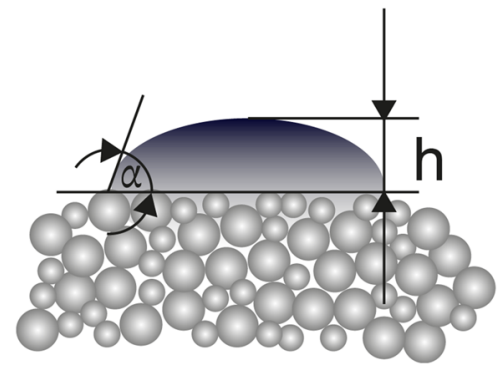

Fig. 3. Scheme of the measurement of the infiltration behavior of the resin in a powder bed.

processing cycles, the bulk density decreases to a value of $0.36 \mathrm{~g} / \mathrm{cm}^{3}$. The packing density of the bulk material can be calculated by dividing the bulk density and the density of the solid material. Thus, the packing density of the used material is $41 \%$ and $37 \%$ for a solid material density of $0.95 \mathrm{~g} / \mathrm{cm}^{3}$.

Besides the influence of the porosity of the substrate material, the influence of the used liquid resin and thus the surface tension and its viscosity on the infiltration behavior was determined. Therefore, the surface tension of the resins Araldite GY 764 and Araldite GY 793 was measured via the pendant drop method and calculated according the Laplace-Young equation. The resin with the trade name Araldite GY 764 shows a value of $\pm 37 \mathrm{Nm} / \mathrm{m}$ higher surface tension than the resin with the trade name Araldite GY $793( \pm 22 \mathrm{Nm} / \mathrm{m})$. Nevertheless, the surface tension cannot be linked directly to the infiltration speed because of the influence of the viscosity and contact angle on the infiltrated volume expressed in Eq. 3.

The viscosity and surface tension determine the absorption behavior of liquids in porous structures according to Eq. 2. For this reason, the temperature-dependent viscosity of the resins was analyzed. Figure 4 shows the complex viscosity dependent on temperature for a heating rate of $2 \mathrm{~K} / \mathrm{min}$. With increasing temperature, the viscosity shows a first decrease, which can be linked to the higher mobility of chain segments with rising temperature. For higher temperatures, the crosslinking or rather curing process takes place and the viscosity rises. The minimum viscosity is reached in a temperature interval between $100^{\circ} \mathrm{C}$ and $120^{\circ} \mathrm{C}$ for both resin and hardener mixtures. The curing reaction starts for a heating rate of $2 \mathrm{~K} / \mathrm{min}$ at a temperature of $100^{\circ} \mathrm{C}$. This value depends on time and temperature, and thus the heating rate plays a major role. Comparing the two resins, the curing behaves almost equally. The system with the trademark Araldite GY793 shows a slight delay in the viscosity increase.

The infiltration behavior of the used resins is shown in Fig. 5. Therefore, the droplet height is plotted against the interaction time. Medium values of at least ten droplets are represented. For a temperature of $20^{\circ} \mathrm{C}$ and a bulk density of 
Table I. Design of experiments

\begin{tabular}{lcr}
\hline Resin & Bulk density powder $\left(\mathbf{g} / \mathbf{c m}^{\mathbf{3}}\right)$ & Temperature $\left({ }^{\circ} \mathbf{C}\right)$ \\
\cline { 2 - 3 } Araldite GY 764 & 0.39 & $20,40,60$ \\
Araldite GY 793 & 0.36 & $20,40,60$ \\
& 0.39 & $20,40,60$ \\
\hline
\end{tabular}

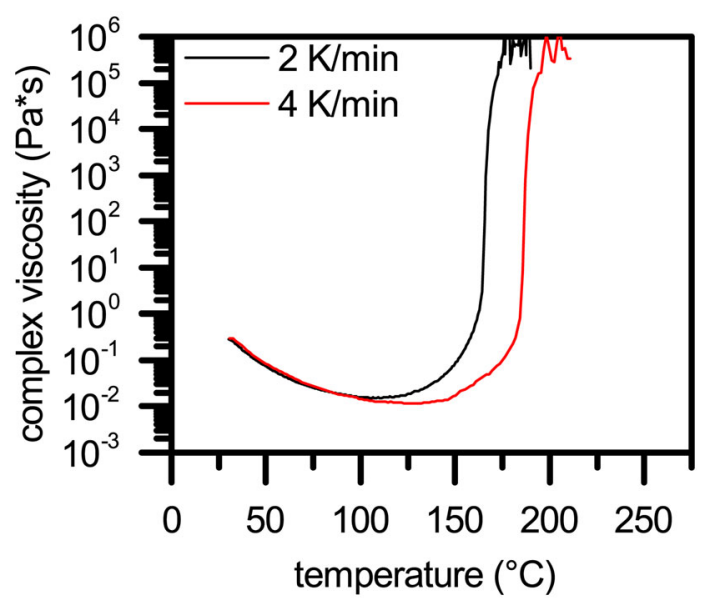

Fig. 4. Viscosity of the used resins.

$0.39 \mathrm{~g} / \mathrm{cm}^{3}$, a total infiltration of the droplet into the substrate cannot be detected for either resin. The initial droplet height is higher for the resin with the trademark Araldite GY 764. This leads to the assumption that the volume of one drop of the resin GY 764 is greater than the volume of the GY793 droplet. The droplet height decreases more quickly during the first $5-10 \mathrm{~s}$ than during the remaining time. With increasing temperature, the infiltration time decreased dramatically for both systems. For a temperature of $60^{\circ} \mathrm{C}$, the total infiltration takes only approximately $2 \mathrm{~s}$. This acceleration of the infiltration process goes along with the reduced viscosity and thus the higher volume of liquid material, which can infiltrate the porous structure according to Eq. 2. For layer times of approximately $40 \mathrm{~s}$ in selective laser sintering, an infiltration time of only $2 \mathrm{~s}$ is favored because the infiltration itself must not enlarge the processing time.

The infiltration behavior of the resins in a substrate shows a higher porosity or rather lower bulk density of $0.36 \mathrm{~g} / \mathrm{cm}^{3}$ (Fig. 5, right). The bulk density of the substrate changes from $0.39 \mathrm{~g} / \mathrm{cm}^{3}$ to $0.36 \mathrm{~g} / \mathrm{cm}^{3}$. This increase of porosity leads to an increase of infiltration speed. At room temperature, the resin with the Araldite GY764 trademark infiltrates the porous structure in $<60 \mathrm{~s}$, whereas for a substrate bulk density of $0.39 \mathrm{~g} / \mathrm{cm}^{3}$ after $80 \mathrm{~s}$ a droplet height of $0.5 \mathrm{~mm}$ is still measurable. For the substrate with the bulk density of $0.36 \mathrm{~g} / \mathrm{cm}^{3}$, the deviation between the minimum and maximum values is larger than for the powder with a bulk density of $0.39 \mathrm{~g} / \mathrm{cm}^{3}$. This may be a result of inhomogeneous packing and thus an irregular infiltration. Comparison of the two resins demonstrates a slightly faster infiltration for Araldite GY 793. As shown before, the infiltration speed increases with rising temperature because of the reduced viscosity of the resins. For temperatures $>60^{\circ} \mathrm{C}$, the absorption of the liquid is even faster and the droplet height cannot be detected any more.

Besides the experimental evaluation of the infiltration or rather absorption behavior, the modelbased description is of main interest. Therefore, the Washburn equation was used to calculate the decrease of droplet height depending on time. As a simplification, the decrease of droplet height was equalized with the infiltration length. This is incorrect because of the volume of the infiltrated particles itself. The form factor in the modified Washburn Eq. 3 is not determined but assumed to be between 0.2 and 0.4 according to the rough surface of the particles and resulting in uneven pore structure. Figure 7 shows the comparison of the measured and calculated droplet height dependent on the infiltration time. The pore diameter was calculated by using the following equation: ${ }^{17}$

$$
D_{\text {Pore }}=\frac{2}{3} \cdot \frac{\varepsilon}{1-\varepsilon} \cdot d_{50,3}
$$

with the porosity $\varepsilon$ and the median particle diameter $d_{50,3}$.

The viscosity value was taken from the measurements in Fig. 4, and the contact angle was idealized as $85^{\circ}$. To determine the droplet height dependent on time, the initial droplet heights of the infiltration measurements were used as default values. For $20^{\circ} \mathrm{C}$, the calculated cure for a form factor of $0.4 \mathrm{fits}$ well to the measured curve. With increasing form factor, the deviation from the measurement becomes bigger. For surrounding temperatures of $40^{\circ} \mathrm{C}$ and $60^{\circ} \mathrm{C}$, the curves with the form factors 0.2 and 0.3 are much closer to the measurements. Therefore, a form factor of 0.3 was chosen for the further calculations (Fig. 6).

A comparison of the modeled and measured infiltrations curves for the different resins, temperatures and bulk densities is represented in Fig. 7. The calculated and measured values partially demonstrate a high level of consistency. Nevertheless, some deviations between the measured and calculated values are visible. This can on the one 

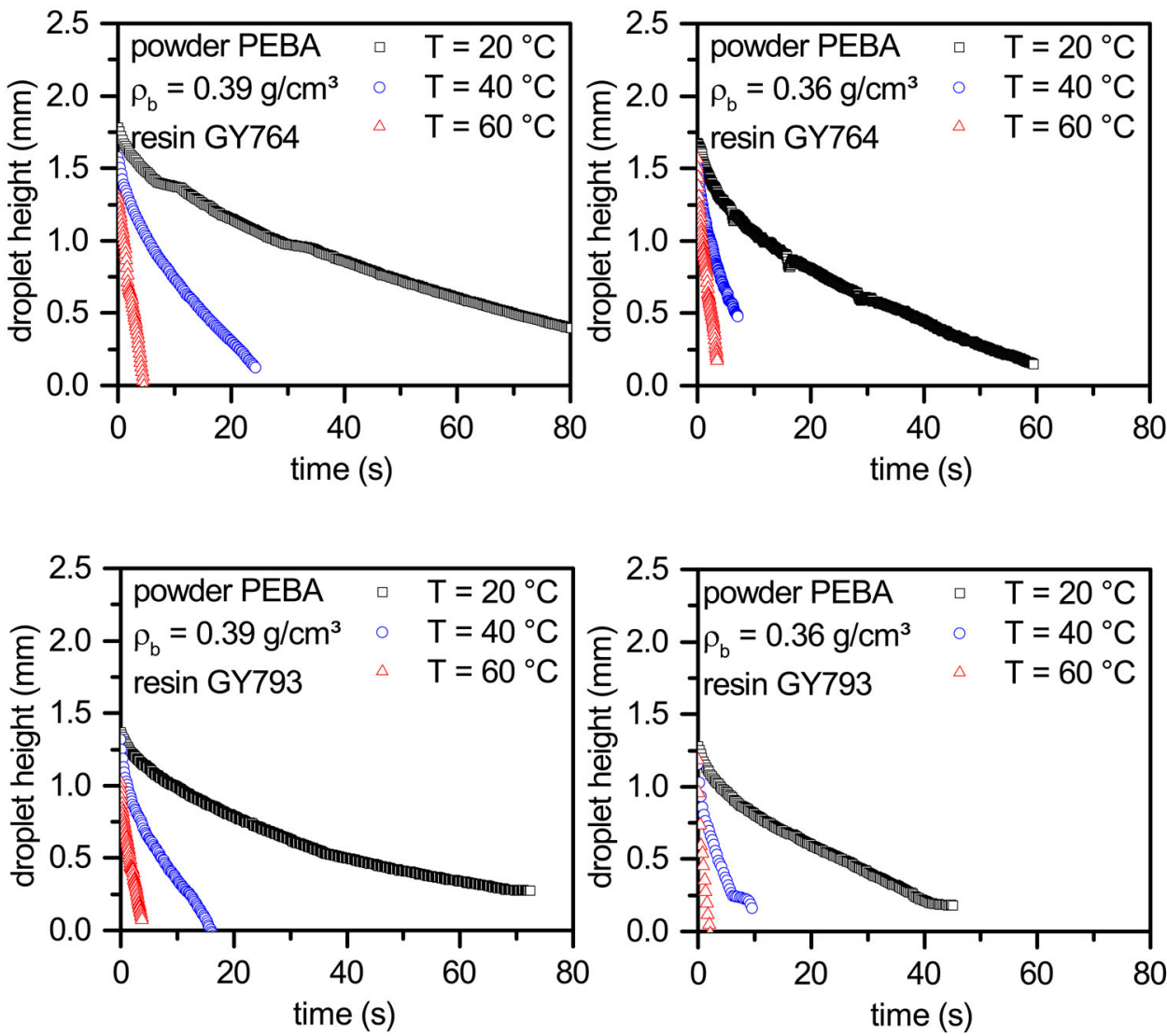

Fig. 5. Droplet height dependent on time for different temperatures, resins and bulk densities.

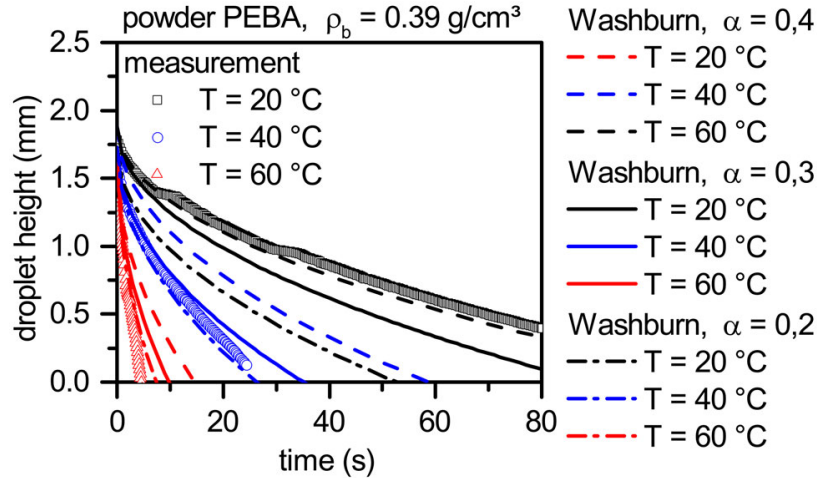

Fig. 6. Comparison of measured and calculated infiltration behaviors for different form factors used in the Washburn equation.

hand be traced back to the measurement uncertainty of the infiltration experiments. Especially for high temperatures, the recording rate of the used camera system is too low. On the other hand, according to the Washburn equation the pores in the bulk materials are assumed to be cylinders even if a form factor was implemented. However, it is a three-dimensional network with different types of pore geometries. Nevertheless, for the simplification and assumptions carried out, the Washburn equation can be used to predict the infiltration behavior of a specific combination of bulk material and liquids.

Besides the calculated and measured infiltration behaviors, the feasibility of the aimed for process must be analyzed. Therefore, Fig. 8 shows microscopy images of a cross section of a sample of PEBA with the GY 764 resin. The samples were prepared in a DTM Sinterstation 2000 selective laser sintering system. The building chamber temperature was $130^{\circ} \mathrm{C}$ (see DSC diagram Fig. 4), and the liquid droplet and the powder material were exposed to a $\mathrm{CO}_{2}$ laser. The images show that the infiltration depth of the liquid is higher than the laser material interaction zone, which is visible as white areas. The used resin is absorbed into a thickness of approximately $1000 \mu \mathrm{m}$. In regions far away from the surface, the PEBA is not molten, and the particles glue together because of the surrounding epoxy material. Nevertheless, these experiments show a principle feasibility of the represented hybrid process.

\section{CONCLUSION}

This article introduces a new hybrid additive manufacturing technique that will overcome the hurdle to manufacturing multi-material parts in one additive process. With selective laser sintering 

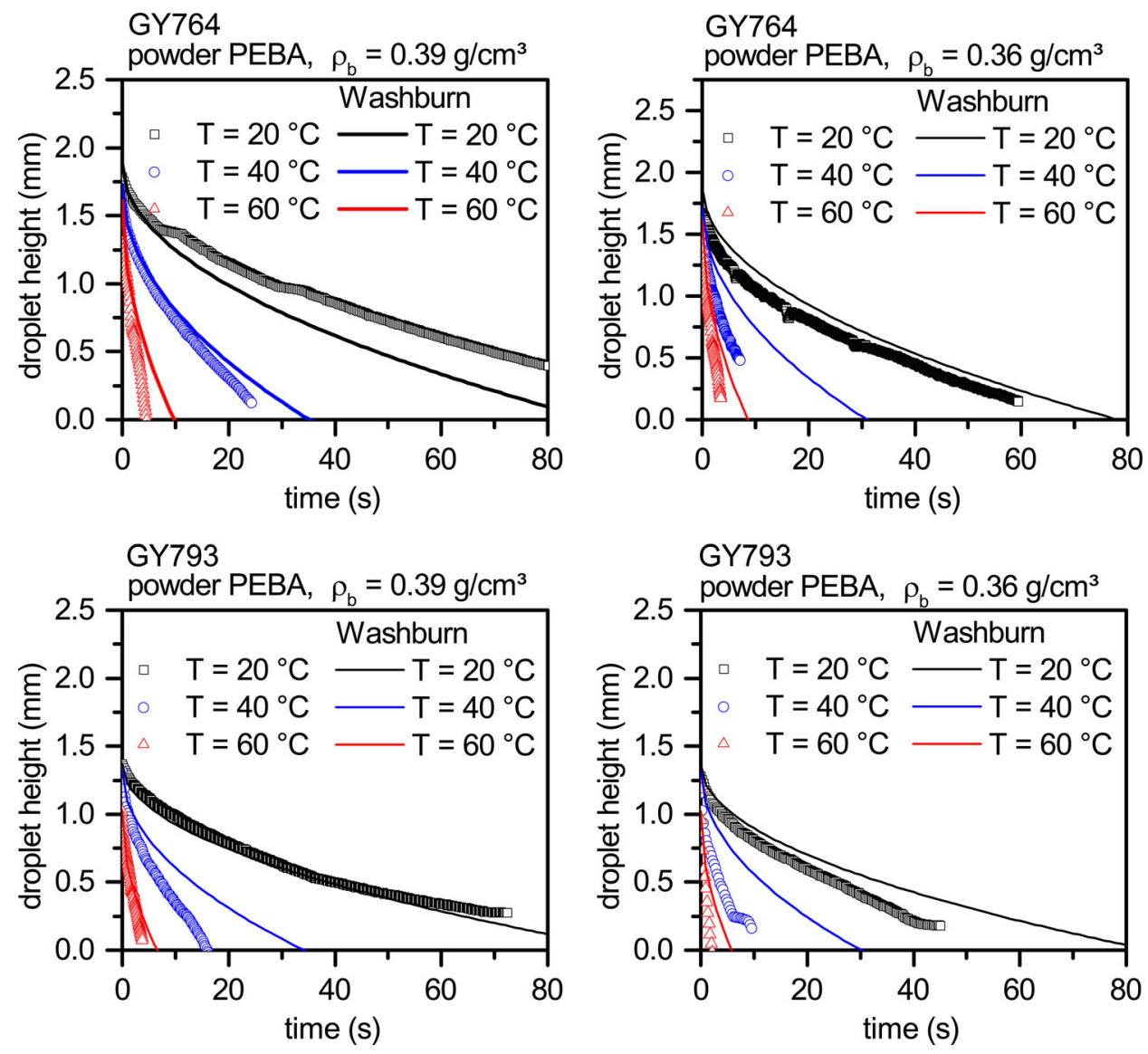

Fig. 7. Droplet height dependent on time for different temperatures and resins; powder: PEBA bulk density $0.36 \mathrm{~g} / \mathrm{cm}^{3}$.
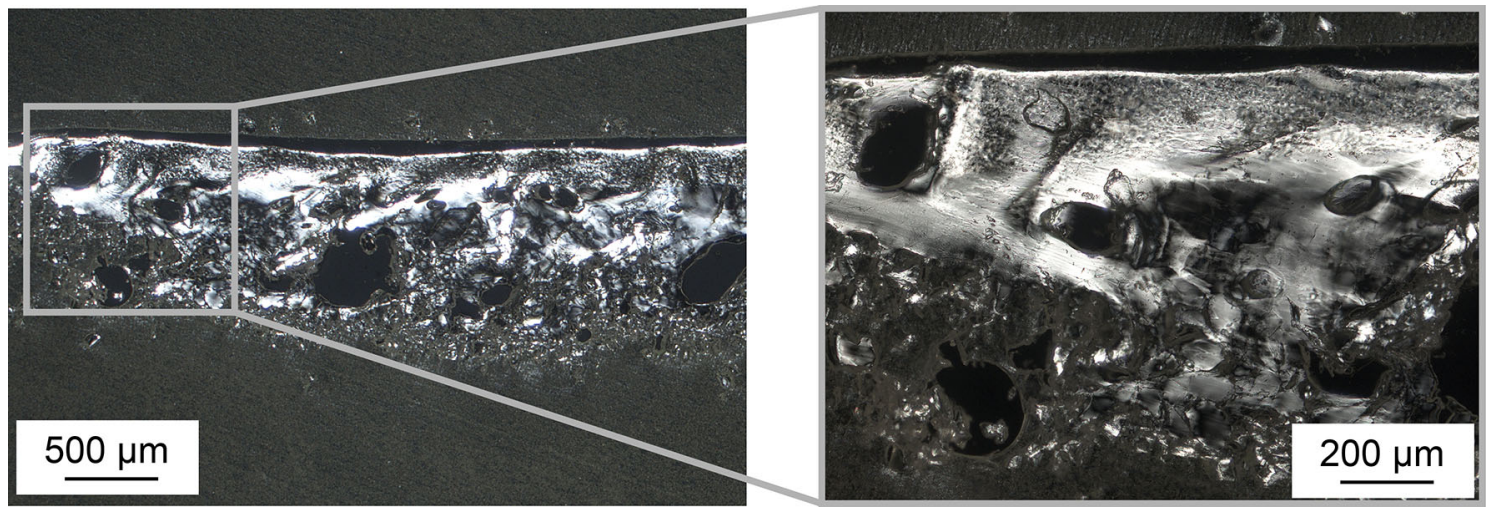

Fig. 8. Microscopy image of PEBA sample, which was infiltrated with a droplet of the resin GY 764.

of plastic, only one material can be processed up to now. The implementation of reactive liquids, such as epoxy resins, in the laser sintering process allows the generation of multi-material parts. Therefore, the curing and infiltration behavior of the used resins has to be understood.

The interaction of the resin with the porous powder bed is investigated with a new test setup. The development of droplet height between the powder bed and liquid was determined and linked to the infiltration behavior. For both analyzed epoxy resins Araldite 764 and Araldite 793, Hardener XB 3473 was used. With increasing temperature, the infiltration process is accelerated for both resins. This goes along with the reduced viscosity with increased temperature. At $20^{\circ} \mathrm{C}$, the resin does not totally infiltrate the powder bed. For the highest analyzed temperature of $60^{\circ} \mathrm{C}$, the infiltration takes $<2 \mathrm{~s}$. This means for layer times in selective laser sintering of $40 \mathrm{~s}$ and processing temperature of the powder bed surface of $120^{\circ} \mathrm{C}$, the infiltration process will not determine the processing time. Thus, the 
analyzed systems can be used in the combined laser sintering process. Nevertheless, the infiltration depth and parallel curing must be analyzed in further investigations. Furthermore, the Washburn equation was used to predict the infiltration behavior of the used combination of powders and liquids. Taking the simplifications into account, good agreement of the calculated and measured values could be shown.

\section{ACKNOWLEDGEMENTS}

The authors thank the German Research Foundation (DFG) for funding Collaborative Research Centre 814 - Additive Manufacturing.

\section{OPEN ACCESS}

This article is distributed under the terms of the Creative Commons Attribution 4.0 International License (http://creativecommons.org/licenses/by/4.0/ ), which permits unrestricted use, distribution, and reproduction in any medium, provided you give appropriate credit to the original author(s) and the source, provide a link to the Creative Commons license, and indicate if changes were made.

\section{REFERENCES}

1. M. Schmid, Selektives Lasersintern (SLS) mit Kunststoffen Technologie, Prozesse und Werkstoffe, 1st ed. (München: Carl Hanser Verlag, 2015), p. 200.

2. D. Eyers and K. Dotchev, Assem. Autom. 201, 39 (2010).
3. J. Schmidt, M. Sachs, S. Fanselow, M. Zhao, S. Romeis, D. Drummer, K.-E. Wirth, and W. Peukert, Chem. Eng. Sci. 156, 1 (2016).

4. J. Schmidt, M. Sachs, M. Zhao, S. Fanselow, K. Wudy, M. Drexler, D. Drummer, K.-E. Wirth, and W. Peukert, AIP Conf. Proc. (2016). https://doi.org/10.1063/1.4942343.

5. A. Wegner, R. Harder, G. Witt, and D. Drummer, Int. J. Recent Contrib. Eng. Sci. IT (iJES) 3, 5 (2015).

6. A. Amado, M. Schmid, and K. Wegener, AIP Conf. Proc. (2015). https://doi.org/10.1063/1.4918509.

7. L. Verbelen, S. Dadbakhsh, M. Van den Eynde, J.P. Kruth, B. Goderis, and P. Van Puyvelde, Eur. Polym. J. 75, 163 (2016).

8. M. Schmid and K. Wegener, Proc. Eng. 149, 457 (2016).

9. M. Schmid, Laser Sintering with Plastics, Technology, Processes, and Materials, 1st ed. (München: Carl Hanser Verlag, 2015), p. 218.

10. A. Gebhardt, Understanding Additive Manufacturing: Rapid Prototyping-Rapid Tooling-Rapid Manufacturing, 1st ed. (München: Carl Hanser Verlag, 2012), p. 168.

11. K. Wudy, Alterungsverhalten von Polyamid 12 beim selektiven Lasersintern (Erlangen: Friedrich-Alexander Universität Erlangen-Nürnberg, 2017), p. 160.

12. R. Holman, M. Cima, S. Uhland, and E. Sachs, J. Colloid Interface Sci. 249, 432 (2002).

13. H. Tan, AIChE J. 63, 1690 (2017).

14. E.W. Washburn, Phys. Rev. 17, 273 (1921).

15. M. Denesuk, G.L. Smith, B.J.J. Zelinski, N.J. Kreidl, and D.R. Uhlmann, J. Colloid Interface Sci. 158, 114 (1993).

16. Resins selector guide (Huntsman Advanced Materials (Switzerland) GmbH), https://www.huntsman.com/advance d_materials/a/Our\%20Technologies/High\%20Performance\% 20Components/Epoxy\%20Resins?p_langswitch=1. Accessed 29 Oct 2018.

17. M. Stieß, Mechanische Verfahrenstechnik- Partikeltechnologie 1, 3rd ed. (Berlin: Springer, 2009), p. 499. 